\title{
OPEN Experimental evaluation of bamboo fiber/particulate coconut shell hybrid PVC composite
}

\author{
Adeolu A. Adediran ${ }^{1 凶}$, Abayomi A. Akinwande², Oluwatosin A. Balogun², O. S. Olasoju ${ }^{3}$ \& \\ Olanrewaju S. Adesina ${ }^{1}$
}

Bamboo fibers (BF) treated in $1.3 \mathrm{Molar} \mathrm{NaOH}$ and particulate coconut shell (PCS) sieved to $-45 \mu \mathrm{m}$ were incorporated into polyvinyl chloride (PVC) matrix towards improving the properties of PVC composite for ceiling boards and insulating pipes which sags and degrade with time needing improvement in properties. The process was carried out via compression moulding applying $0.2 \mathrm{kPa}$ pressure and carried out at a temperature of $170^{\circ} \mathrm{C}$. Composites developed were grouped according to their composition. Groups A, B, C, and D were infused with 2, 4, 6 and 8 wt\% PCS at constant amount, respectively. Each group was intermixed with a varying proportions of $\mathrm{BF}(0-30 \mathrm{wt} \%$ at $5 \%$ interval). Tests carried out on the samples produced revealed that the yield strength, modulus of elasticity, flexural strength, modulus of rupture were enhanced with increasing BF proportion from 0 to $30 \mathrm{wt} \% \mathrm{BF}$ at $2 \mathrm{wt} \%$ constant PCS input. Thermal and electrical properties trended downward as the fiber content reduced even as the hardness was enhanced with PCS/BF intermix which was also reflected in the wear loss index. Impact strength was highest on the infix of $4 \mathrm{wt} \%$ PCS and $15 \mathrm{wt} \%$ BF. Compressive strength was better boasted with increasing fiber and PCS amount but 8 wt\% PCS amounted to depreciation in trend. It was generally observed that PCS performed optimally at $2 \mathrm{wt} \%$ incorporation while beyond that resulted in lowering of strength. Blending of the two variable inputs; 0-30 wt\% BF and $2 \mathrm{wt} \%$ PCS presented better enhancement in properties.

In recent years, composites are designed to achieve certain configurations and requirements (for structural, electronic packaging, automobile, aerospace, and household applications). These composites possess improved strength to weight properties, low density, and they are relatively cheap. Owing to increase in the amount of composite materials being adopted globally, researches are being tailored towards the development of biodegradable filler reinforced composites. Bio-fillers possess improved specific strength and modulus and impact as a measure of resistance to crack propagation when used as reinforcements in a polymer matrix. In addition, the overall cost of composite production is reduced ${ }^{1-3}$.

Composites materials are engineered by the combination of two or more distinct constituents, where one of the constituents is referred to as the matrix material and the other is known as the reinforcing material. Additionally, embedding of the reinforcing phase into the matrix material is done at a macroscopic scale. The distinct phases maintain their inherent physical and chemical properties. Matrix material serves the role of shielding the fibers from chemical and environmental attacks (like sunlight, heat, and moisture). They keep the fibers in place while ensuring effective load transfer among fiber strands. The toughness of the composite formed depends on the type of matrix adopted ${ }^{4,5}$. In addition, the matrix gives aesthetic value and good surface finish to the developed composite. On the other hand, the reinforcing phases could serve as the major load carrying component ${ }^{6}$.

Numerous studies have highlighted the importance of various bio-fillers (majorly from agro-products) and their environmental advantages which include reduced consumption of nonrenewable materials and lowering of greenhouse gas emissions which in turn reduce environmental pollution ${ }^{7-10}$. Natural fibers like bamboo ${ }^{11}$, jute ${ }^{12}$, oil palm ${ }^{13}$, cotton ${ }^{14}$, and sisal ${ }^{15}$ amongst others are ligno-cellulose based materials which are environmentally

${ }^{1}$ Department of Mechanical Engineering, Landmark University, PMB, Omu-Aran 1001, Kwara State, Nigeria. ${ }^{2}$ Department of Metallurgical and Materials Engineering, Federal University of Technology, Akure, Ondo State, Nigeria. ${ }^{3}$ Faculty of Material Science and Chemical Engineering, Ningbo University, Ningbo, China. ${ }^{\otimes}$ email: adediran.adeolu@Imu.edu.ng 


\begin{tabular}{|l|l|l|l|}
\hline Parameter & Length & Diameter & Aspect ratio \\
\hline Value & $20 \mathrm{~mm}$ & $0.25 \mathrm{~mm}$ & 80 \\
\hline
\end{tabular}

Table 1. Properties of bamboo fibers used.

friendly substitutes over the synthetic (Kevlar, glass and carbon) fibers being used in time past ${ }^{16,17}$. Other attractive properties of natural fibers are good toughness, renewability, biodegradability, cost effectiveness, good specific strength, light weight, availability, non-toxic in nature, and the tools used in processing them are not abraded $^{18,19}$.

Howbeit, natural fillers possess several disadvantages such as poor adhesion with the polymeric matrix owing to their hydrophilic nature, they possess the tendency to degrade when employed in high temperature applications ${ }^{20,21}$. These fillers are usually of inhomogeneous dimensions, they have low melting point and high moisture absorption characteristics which culminate in degradation while in use. Literatures have singled out the importance of chemical treatments in reducing the hydrophilicity of natural fillers and improving the interfacial adhesion created between the hydrophobic matrix and reinforcement ${ }^{22,23}$. Examples of chemical treatments used in overcoming the aforementioned disadvantages are alkalization ${ }^{24,25}$, benzoylation ${ }^{26}$, acrylation ${ }^{27}$, silane ${ }^{28}$, and flame retardant treatments ${ }^{29,30}$.

The use of bamboo is attracting significant attention by dint of their availability, good mechanical characteristics, recyclability, and their service performance can be compared to that of synthetic fiber. Bamboo wastes have been used in the form of fibers, particulates, and ash. A study carried out by Ref. ${ }^{31}$ showed that chemical treatment of $0.5 \mathrm{M} \mathrm{NaOH}$ solution effectively modified the surface of bamboo fiber by increasing the number of sites available for mechanical interlocking with high density polyethylene matrix. This culminates in improved mechanical properties. Optimum performance was achieved at $2-4 \mathrm{wt} \%$ bamboo fiber addition. The research of $^{32}$ studied the effect of alkali treatment on bamboo fibers at 2, 6, and $10 \% \mathrm{NaOH}$ solution for a period of $12 \mathrm{~h}$. The study highlighted that $6 \% \mathrm{NaOH}$ showed the optimum performance for the development of bamboo fiber reinforced composite, which was also adopted in this study. The study also established the fact that mechanical properties such as fracture toughness and flexural modulus depend on fiber length. Where increase in the length of bamboo fibers was accompanied by a corresponding increase in the aforementioned properties. Thermal stability and biodegradability of matrix can be improved with the addition of bamboo fiber as reported by Ref. ${ }^{33}$ who reported improved flexural strength, water absorption characteristics. Decreased in weight loss was observed when the samples were buried in the soil. Furthermore, the addition of bamboo fiber to polypropylene showed improvement in mechanical properties up to $50 \%$ by weight of the matrix as revealed ${ }^{34}$. Considerable efforts toward improving the performance of bamboo show that the use of compactibilizers such as maleated elastomer modifier in composites shows better properties compared to unmodified samples ${ }^{35,36}$.

Contemporary studies have shown that fiber and particulate reinforcement can be combined to improve the properties of polymeric matrix by the formation of hybrid composites with precise configuration, which has been a major focus of research in the last 20 years $^{37-39}$. Nevertheless, none had considered intermix of bamboo fiber and particulate coconut shell in PVC matrix; a feat implemented in this study towards property enhancement of PVC.

Coconut shell is a non-edible hard part of coconut, which is widely regarded as waste and dumped in landfills. This shell possesses good strength and modulus, it is rigid and usually grown in the tropical areas of Africa. Coconut shell in previous researches has shown the ability to improve the compressive strength when incorporated into epoxy matrix ${ }^{40}$. More $\mathrm{so}^{41}$, proved that treatment of coconut shell with $1 \% \mathrm{NaOH}$ solution increased the mechanical properties and thermal stability of unsaturated polyester when homogenous dispersion was achieved between the matrix and reinforcement. PVC is light, with good electrical insulation, corrosion and weathering resistance, abrasion resistance and cost effective. As a result of the good electrical insulation property its used as insulation pipes in running electrical pipes, also owing to good thermal insulation, it is employed in celing board application. However, these pipes are observed to degrade with time; evident in sagging and cracking before eventual failure of this pipes. This is ascribable to low mechanical properties which can be improved by the incorporation of fiber and particulate as noted in previoud study ${ }^{42-44}$. Therefore, from the literature review and the salient properties exhibited by bamboo fiber and coconut shell particulate, this study considered it a worthwhile to study the influence of these reinforcements at varied weight fraction on the properties of polyvinyl chloride towards improving properties of PVC base material for ceiling board and insulation pipes material.

\section{Materials and methods}

Materials and processing. Materials utilized in this study include sodium hydroxide, hydrochloric acid, bamboo fiber, coconut shell, and polyvinyl chloride pellets. Prior to chemical treatment, bamboo fibers (properties highlighted in Tables 1 and 2) and shells obtained as wastes were sundried for 7 days, treated, and used for composite development. Similar to procedure employed in $^{45,46}$, bamboo fiber was treated with $1.3 \mathrm{Molar} \mathrm{NaOH}$ solution, the medium for a period of $12 \mathrm{~h}$ and then washed with distilled water followed by sun drying for 7 days. Similar to ${ }^{45}$, coconut shell was treated with of 1.3 Molar sodium hydroxide for impurities removal after which the shell was washed in water at $50{ }^{\circ} \mathrm{C}$ and sundried for 3 days to ensure complete dryness. Sequel to this was the grinding, pulverizing and sieving of the shell using using laboratory sieve shaker in line with ASTM D6913-17 ${ }^{47}$ to obtain a coconut shell particle size of $-45 \mu \mathrm{m}$ which was used along with bamboo fiber as reinforcing materials in polyvinyl chloride matrix.

The parameter (length, diameter and aspect ratio) for the bamboo fiber used in the course of the study is highlighted in Table 1 . Table 2 higlights the chemical composition of bamboo fiber before and after treatment. 


\begin{tabular}{|l|l|l|}
\hline Composition & Amount before $\mathrm{NaOH}$ treatment (\%) & Amount after $\mathrm{NaOH}$ treatment (\%) \\
\hline Cellulose & 52.3 & 58.97 \\
\hline Hemicellulose & 23.7 & 19.5 \\
\hline Lignin & 14.6 & 10.3 \\
\hline Ashes and water content & 7.4 & 4.6 \\
\hline Other & 2.0 & 6.63 \\
\hline
\end{tabular}

Table 2. Chemical composition of treated bamboo fiber.

\begin{tabular}{|l|c|}
\hline Compound present & Coconut shell powder \\
\hline $\mathrm{SiO}_{2}$ & 53.67 \\
\hline $\mathrm{CaO}$ & 5.56 \\
\hline $\mathrm{Al}_{2} \mathrm{O}_{3}$ & 11.12 \\
\hline $\mathrm{Fe}_{2} \mathrm{O}_{3}$ & 6.21 \\
\hline $\mathrm{Na}_{2} \mathrm{O}$ & 1.14 \\
\hline $\mathrm{MnO}$ & 1.35 \\
\hline $\mathrm{P}_{2} \mathrm{O}_{5}$ & 0.22 \\
\hline $\mathrm{MgO}$ & 3.08 \\
\hline $\mathrm{Na} 2$ & 1.14 \\
\hline Others & 8.92 \\
\hline LOI & 7.59 \\
\hline
\end{tabular}

Table 3. Properties of coconut shell powder. LOI loss on ignition.
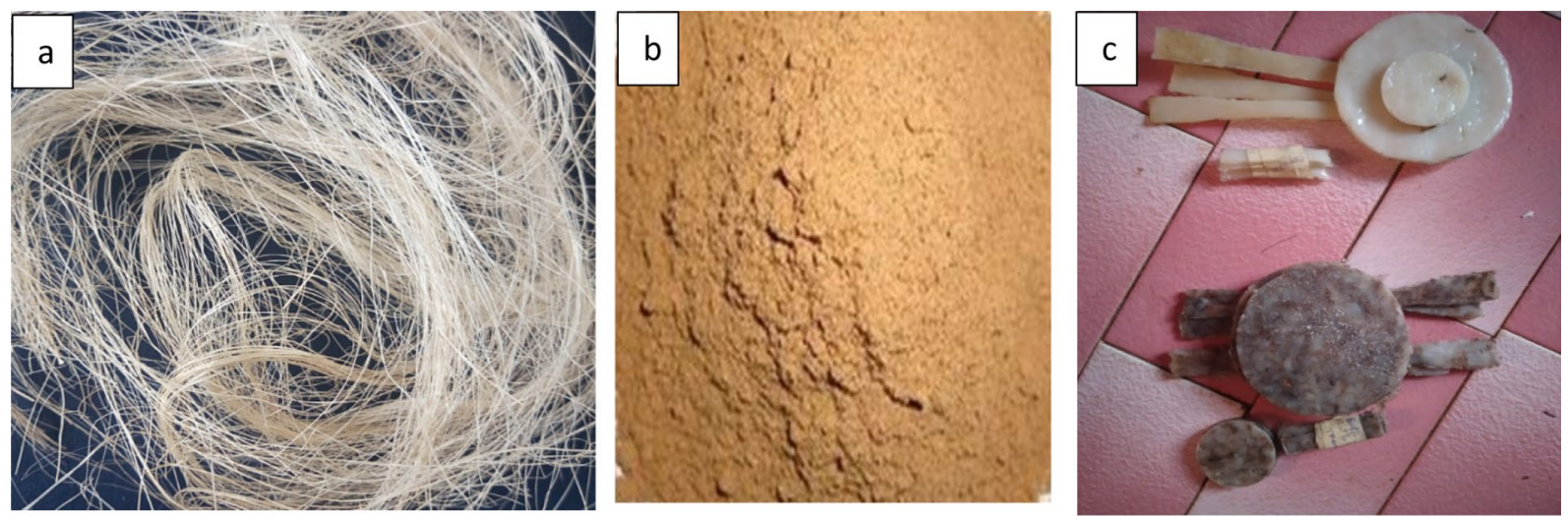

Figure 1. Pictures of (a) bamboo fiber (b) coconut shell powder c some composites samples developed.

Results content having highest proportion revelaed increase in cellulose content, reduction in hemicellulose, lignin and ash and water content.

Table 3 reveals the chemical composition of coconut shell powder with silica $\left(\mathrm{SiO}_{2}\right)$ sharing the highest content followed by alumina $\left(\mathrm{Al}_{2} \mathrm{O}_{3}\right)$ which are strength enhacing media, contributiong to strength of composite. Figure $1 \mathrm{a}-\mathrm{c}$ show the pictorial representative of the bamboo fiber, coconut shell powder and the composites developed respectively.

Composite development. Cast iron moulds with dimensions of $150 \times 50 \times 3\left(\mathrm{~mm}^{3}\right)$ and dumb bell shape, mould cavity of $3 \mathrm{~mm}$ thickness and length of $150 \mathrm{~mm}$ were adopted for the production of specimens used for the evaluation of flexural and tensile properties respectively. Petroleum jelly was applied on the mould surfaces for easy removal of specimens. Prior to composite production, the moulds used were cleaned to remove the residual polymeric material present on the surface of the mould.

Bamboo fiber and particulate coconut shell were incorporated into polyvinyl chloride matrix in varying proportions as categorized in group A (containing 2 weight percent (wt\%) proportion of CSP and varying proportion of $\mathrm{BF}$ at $0-30 \mathrm{wt} \%$ ), group B (containing $4 \mathrm{wt} \%$ proportion of CSP and varying proportion of BF at $0-30 \mathrm{wt} \%$ ), group $\mathrm{C}$ (containing $6 \mathrm{wt} \%$ proportion of CSP and varying proportion of $\mathrm{BF}$ at $0-30 \mathrm{wt} \%$ ) and group $\mathrm{D}$ (containing $8 \mathrm{wt} \%$ proportion of CSP and varying proportion of BF at $0-30 \mathrm{wt} \%)$ as represented in Table 4 . Compression 


\begin{tabular}{|c|c|c|c|c|c|c|c|c|c|c|c|}
\hline \multicolumn{3}{|c|}{$\begin{array}{l}\text { Group A ( } 2 \text { wt } \% \\
\text { CSP) }\end{array}$} & \multicolumn{3}{|c|}{$\begin{array}{l}\text { Group B ( } 4 \text { wt } \% \\
\text { CSP) }\end{array}$} & \multicolumn{3}{|c|}{$\begin{array}{l}\text { Group C (6 wt } \% \\
\text { CSP) }\end{array}$} & \multicolumn{3}{|c|}{$\begin{array}{l}\text { Group D (8 wt\% } \\
\text { CSP) }\end{array}$} \\
\hline BF & CSP & PVC & BF & CSP & PVC & BF & CSP & PVC & BF & CSP & PVC \\
\hline \multicolumn{12}{|c|}{ Mix proportion of specimen produced at varying content of BF and CSP } \\
\hline 0 & 3 & 97 & 0 & 6 & 94 & 0 & 9 & 91 & 0 & 12 & 88 \\
\hline 5 & 3 & 92 & 5 & 6 & 89 & 5 & 9 & 86 & 5 & 12 & 83 \\
\hline 10 & 3 & 87 & 10 & 6 & 84 & 10 & 9 & 81 & 10 & 12 & 78 \\
\hline 15 & 3 & 82 & 15 & 6 & 79 & 15 & 9 & 79 & 15 & 12 & 73 \\
\hline 20 & 3 & 77 & 20 & 6 & 74 & 20 & 9 & 71 & 20 & 12 & 68 \\
\hline 25 & 3 & 72 & 25 & 6 & 69 & 25 & 9 & 66 & 25 & 12 & 63 \\
\hline 30 & 3 & 67 & 30 & 6 & 64 & 30 & 9 & 61 & 30 & 12 & 58 \\
\hline
\end{tabular}

Table 4. Mix proportion. Wt\% is by weight percent of PVC.

moulding machine was used to produce pure polyvinyl chloride and hybrid BF/CSP composites. Specimens were compressed at $170{ }^{\circ} \mathrm{C}$ for a period of $10 \mathrm{~min}$ while employing a pressure of $0.2 \mathrm{kPa}$. Teflon sheet was used to cover the upper and lower part of the mould to avoid burning of the composites which may result from direct heating of metallic plates while petroleum jelly was applied on the mould surface for easy removal of specimens.

Property evaluation. Tensile properties and flexural properties. To assess the behaviour of the specimens when subjected to tensional stress, ultimate tensile strength, and elastic modulus were evaluated using the Universal testing machine (Instron 3369 Series) according to ASTM D3039M-1748 for procedure for tensile. Specimens were evaluated in commensuration with $^{48}$ employing a load of $10 \mathrm{~kg}$ at room temperature $\left(27^{\circ} \mathrm{C}\right)$. Specimens with a gauge length of $150 \mathrm{~mm}$ as stipulated in D $638-14^{49}$ were used in estimating the tensile properties. Three specimens were evaluated and their average was presented as the result.

Flexural strength and modulus at the peak of hybrid composites developed was assessed by subjecting the specimens to a three-point bending load with the aid of a universal testing machine (Instron 3369 Series) in concert with ASTM D790-17 $7^{50}$. Flexural properties were probed at room temperature while adopting a $0.3 \mathrm{~mm} / \mathrm{mm}$ cross head speed and a constant strain rate of $10^{-3} / \mathrm{s}$ to fracture three specimens of $150 \times 50 \times 3\left(\mathrm{~mm}^{3}\right)$ dimension to obtain the average value for each weight fraction.

Relative density and water retention. Density of the composites developed was evaluated using the analytical weighing balance of high precision. Samples of each composites sample were measured to determine their mass and divided by its volume. Samples were immersed in a water medium of $250 \mathrm{~cm}^{3}$ for 7 days to evaluate this property. Water retention was appraised in accordance to ASTM D5229M-12 $2^{51}$ Prior to the immersion, the initial mass of each composite sample was weighed using an analytical balance. The resulting weight gained was recorded for each day to estimate the total weight gained after 7 days.

Izod impact strength and compressive strength. Impact test was used to evaluate the toughness of the bamboo/ coconut shell composite reinforced polyvinyl chloride composite. Three identical specimens were notched in a V-shape and subjected to an impact test in accordance with ASTM D256-10 $0^{52}$ using an Izod impact testing machine. Samples were clamped and the pendulum was set at an angle of $165{ }^{\circ} \mathrm{C}$ to fracture the samples. In accordance to ASTM D $695-15^{53}$, the compressive strength was assessed by subjecting pure polyvinyl chloride and bamboo/coconut shell composite reinforced polyvinyl chloride composite to a compressive load. Three samples were assessed for each composition to determine their average value.

Hardness and wear loss index. Hardness of the pure polyvinyl chloride and polyvinylchloride based composites were appraised in congruent with ASTM D 785- $08^{54}$ utilizing Rockwell hardness tester. Specimens of each weight fraction were positioned on the flat plate and indented using a diamond indenter to diminish the effect of surface. Specimens were indented 5 times on the surface to determine their average value which was employed for analysis.

Wear test was conducted to appraise the wear properties of the samples and for example, their sustainability in any application which involves contact and results in wear. This property was evaluated using Taber abraser (TSC-A016) in concert with ASTM D1044-13 ${ }^{55}$. The equipment was operated at a speed of $150 \mathrm{rpm}$ for a period of $10 \mathrm{~min}$. Samples were weighed using an analytical balance prior to the test and the final weight was also recorded to estimate the wear undergone by each sample.

Thermal conductivity and electrical conductivity. Thermal conductivity was examined to determine the rate at which heat is transmitted from one side of the polymeric composite to the other. Lee's disk apparatus was used for evaluating this property in accordance to ASTM E $1530^{56}$ by appraising samples with a diameter of $50 \mathrm{~mm}$ and $4 \mathrm{~mm}$ radius. While the efficiency of the samples to conduct electric charge was carried out in concert with ASTM D 257-14 ${ }^{57}$ using Agilent 4339 B high resistance meter. 


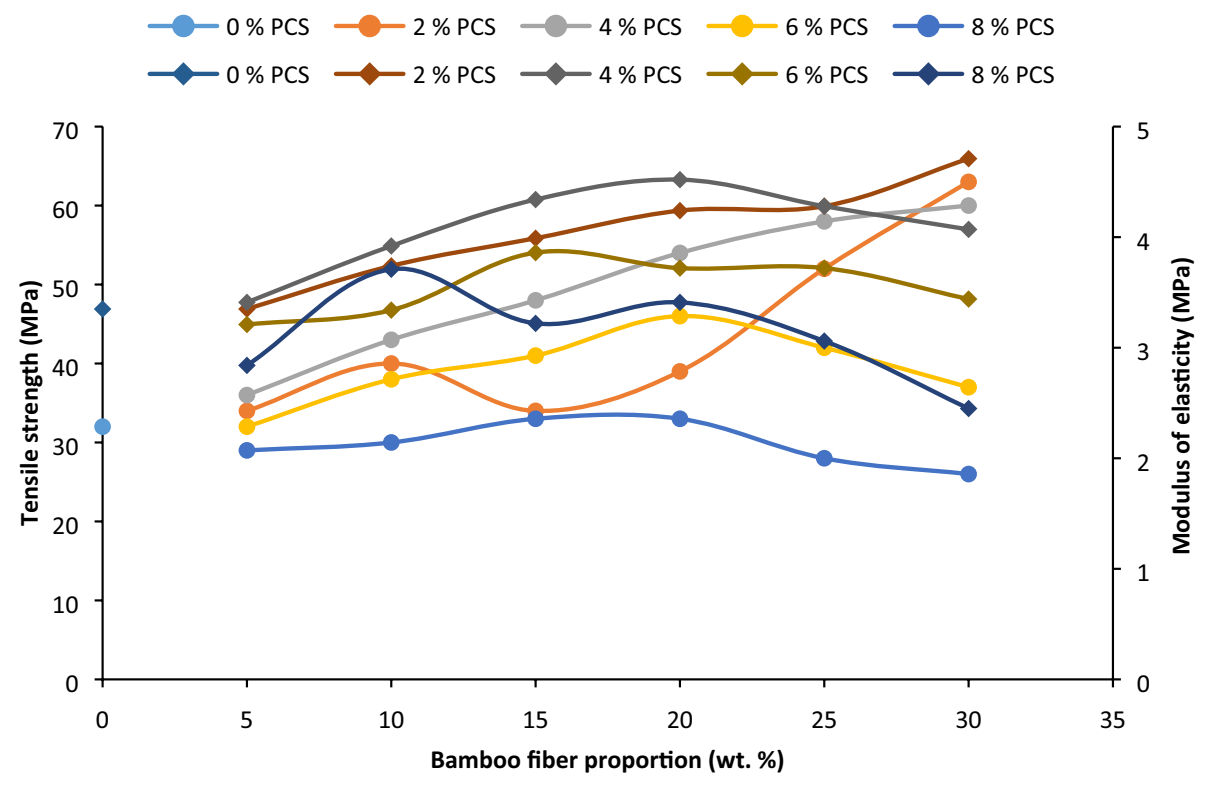

Figure 2. Influence of bamboo fiber fraction on tensile strength and modulus of elasticity for $0,5,10,15,20,25$ and $30 \mathrm{wt} \%$ fiber loading.

\section{Results and discussion}

Tensile properties. Tensile strength. The behavior of the developed BF/PCS composite under tensile loading is as presented in Fig. 2. Variations in fiber and particulate loading affect the tensile behaviour of the composites. At $2 \%$ PCS, the tensile strength was observed to increase with fiber loading from 5 to $30 \mathrm{wt} \%$ presenting an increase of up to $63 \mathrm{MPa}$ at $30 \mathrm{wt} \% \mathrm{BF}$ when compared with $0 / 0$ of $\mathrm{BF} / \mathrm{PCS}$. The rise may be due to coalesce of the fiber and filler particulate ${ }^{58}$. Good wettability of the particulate and BF fiber to the matrix enhanced adhesion, thereby inhibiting dislocation movement ${ }^{59}$. Incorporation of $4 \mathrm{wt} \% \mathrm{PCS}$, tensile strength appreciated in values from 5 to $20 \mathrm{wt} \%$ which can be linked to enhanced interfacial adhesion between fiber and matrix and proper filling of PCS. Admixture of $25-30 \mathrm{wt} \% \mathrm{BF}$ and $4 \mathrm{wt} \%$ PCS resulted in a reduction in tensile strength observed occasioned by possible coagulation of particles (Fig. 8), of which the agglomeration point served as the region of storage of residual stress within the matrix ${ }^{60}$. Similarly, the same experience was noted when the particle portion was 6 and $8 \mathrm{wt} \%$. General trend noted is that the tensile strength improved with fiber loading up to $20 \mathrm{wt} \%$ for particulate presence of $2-8 \mathrm{wt} \%$, while it increased from 5 to $30 \mathrm{wt} \%$ for $2 \mathrm{wt} \%$ particle loading.

Increasing PCS proportion beyond $4 \mathrm{wt} \%$ amounted to lower tensile strength. Observation (Fig. 2) made with intermix of $2 \mathrm{wt} \%$ PCS and $0-30 \mathrm{wt} \%$ BF corroborates the observations made by ${ }^{61-64}$ in which tensile strength trended upward from 0 to $30 \mathrm{wt} \%$. Also, the study of ${ }^{65}$ revealed an increase in tensile strength up to $6 \mathrm{wt} \%$ particulate cassava peel in the presence of $4.5 \mathrm{wt} \%$ palm kernel shell fiber.

Modulus of elasticity (MOE). Modulus of elasticity as represented in Fig. 2 shows an appreciation in MOE values with increased fiber loading up to $30 \mathrm{wt} \%$ at $2 \mathrm{wt} \%$ of PCS addition on account of enhanced interfacial bonding and coalesce of fibers and particulate. Incorporation of 4, 6, and $8 \mathrm{wt} \%$ PCS, there was an uptrend in MOE fiber on integration of 5-20 wt $\%$ BF, while a reduction in MOE was observed on addition of 25-30 wt $\%$ $\mathrm{BF}$, based on stress concentration and possible friction between particles and fiber, the consequence of which amounted to lower stiffness. Authors ${ }^{65}$ achieved higher MOE when $6 \mathrm{wt} \%$ particulate was incorporated in epoxy, the result of which affirms our finding of this study. In this case, integration of BF up to $20 \mathrm{wt} \%$ gave the maximum value for all particulate additions. Presence of fibers and particulates forms an obstacle to the free movement of dislocation ${ }^{66}$ effectuating the enhanced stiffness. According to ${ }^{67}$, the enhanced MOE as $10 \mathrm{wt} \%$ Doum Palm Shell Particle (sieved to 150 and $300 \mu \mathrm{m}$ ) in polypropylene. The result also confirms to the observation of ${ }^{68}$ in which egg shell powder improved the modulus of elasticity of polypropylene. MOE was noted to depreciate from 20 to $35 \mathrm{wt} \%$ particulate in ${ }^{69}$.

Flexural properties. Flexural strength. From the plot in Fig. 3, it was noted that the flexural strength increased with fiber loading amounting to the attenuation of flexural strength on the addition of $2 \mathrm{wt} \% \mathrm{BF}$. This occurred by dint of coalesce between BF and PCS. Flexural strength on incorporation of 4, 6 wt $\%$ PCS amounted to accretion in FS value at fiber loading 5-20 wt\% after which there was a decline in value (from 25 to $30 \mathrm{wt} \%$ ). Inclusion of $8 \mathrm{wt} \%$ PCS impart a rise in flexural strength up to $10 \mathrm{wt} \% \mathrm{BF}$ after which there was a progressive reduction in strength. The reason for this is on account of the agglomeration of filler particles (PCS), hence serving as a point of stress concentration. Authors ${ }^{70}$ assigned this event to poor stress transfer within interfaces. The highest flexural strength was $60 \mathrm{MPa}$ at BF/PCS fraction of $30 / 3 \mathrm{wt} \%$; a rise of $61 \%$ relative to proportion of $0 / 0 \mathrm{wt} \%$ additive. Highest value for flexural strength on addition of 4,6 , and $8 \mathrm{wt} \%$ PCS are 52.8, 44.5, and 


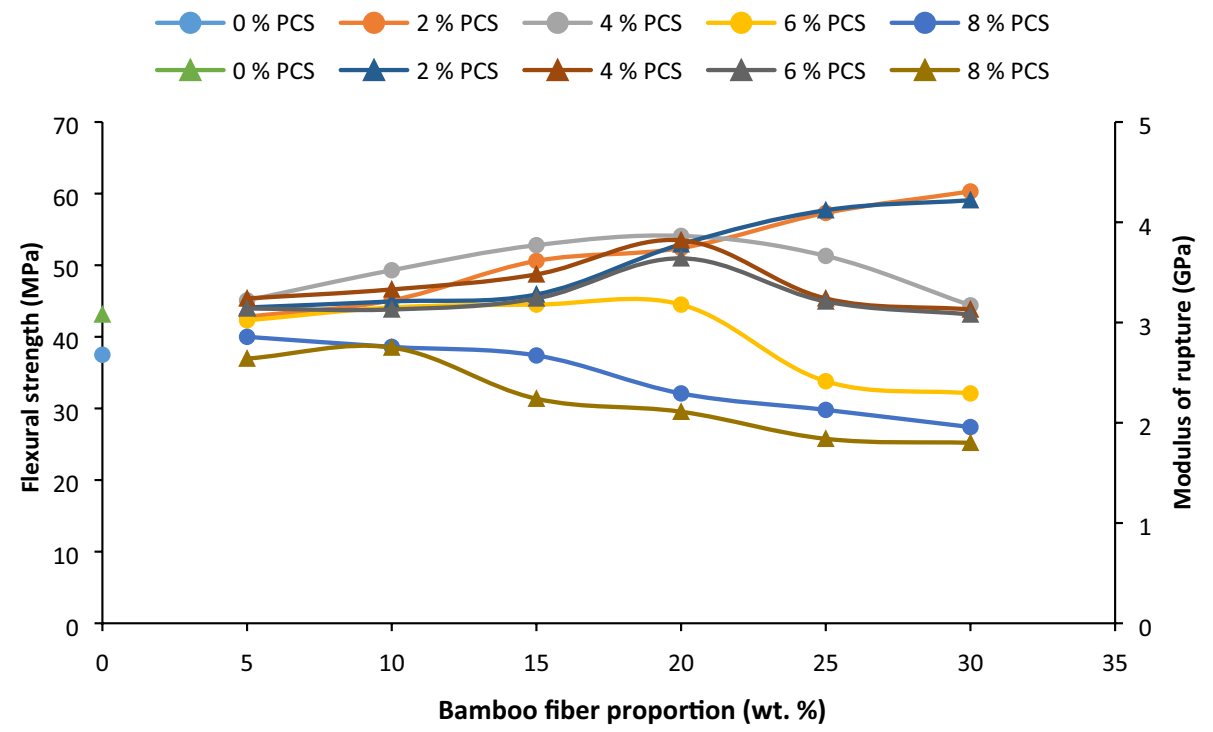

Figure 3. Influence of bamboo fiber fraction on flexural strength and modulus of rupture for $0,5,10,15,20,25$ and $30 \mathrm{wt} \%$ fiber loading.
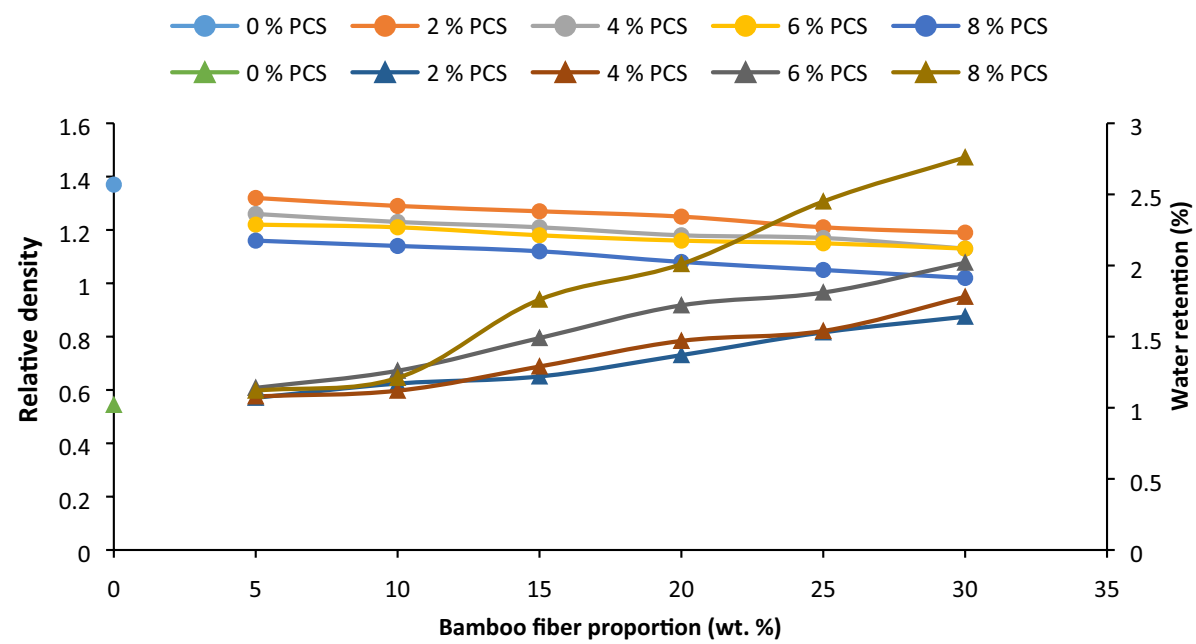

Figure 4. Influence of bamboo fiber fraction on relative density and water retention for $0,5,10,15,20,25$ and $30 \mathrm{wt} \%$ fiber loading.

38.6 MPa. This discloses a reduction in flexural strength with higher PCS proportion based on particulate agglomeration and fiber entanglement.

Modulus of rupture. Modulus of rupture (MOR) similarly followed the same pattern as unfolded in Fig. 3. MOR improved on the integration of $2 \mathrm{wt} \%$ PCS and fiber proportion $5-30 \mathrm{wt} \%$. Enhancement in rigidity is attributable to enhanced interfacial bonding between fiber/particulate and matrix. Blending of $6 \mathrm{wt} \%$ of matrix showed enhancement in rigidity from 5 to $20 \mathrm{wt} \% \mathrm{BF}$; result which corroborates the observations made in $^{71,72}$. Similar experience occurred when $6 \mathrm{wt} \%$ PCS in FM rose from 5 to $20 \mathrm{wt} \%$, although at reducing value when compared with the value obtained under $4 \mathrm{wt} \%$. Studies of ${ }^{33-75}$ affirm the result obtained. Utilization of bamboo fiber in ${ }^{76}$ presented an uptrend in modulus of rupture of epoxy-bamboo fiber composites up to $30 \mathrm{wt} \% \mathrm{BF}$ affirming the usefulness of bamboo fiber in improving flexural rigidity. Reduction in rupture modulus from 25 to $30 \mathrm{wt} \% \mathrm{BF}$ $\left(2,4\right.$, and $6 \mathrm{wt} \%$ PCS) and $15-30 \mathrm{wt} \% \mathrm{BF}(12 \mathrm{wt} \%$ PCS $)$ is linked to entanglement with the matrix ${ }^{58}$. The highest value was recorded on the blending of $30 \mathrm{wt} \% \mathrm{BF} / 3 \mathrm{wt} \%$ PCS value of 4.71 ( $0 / 0 \mathrm{wt} \%$ additive) by $53 \%$.

Density and water retention capacity. Relative density. The density of BF/BCF-PVC composite varied with additive proportion (Fig. 4). Average density of the sample containing $0 / 0$ additive is 1.37 , meanwhile this value reduced on the inclusion of $2,4,6$, and $8 \mathrm{wt} \%$ PCS and $5 \mathrm{wt} \%$ fiber. It was observed that with increasing proportion of PCS, the density reduced owing to the light weight of particulate coconut shell. The results 


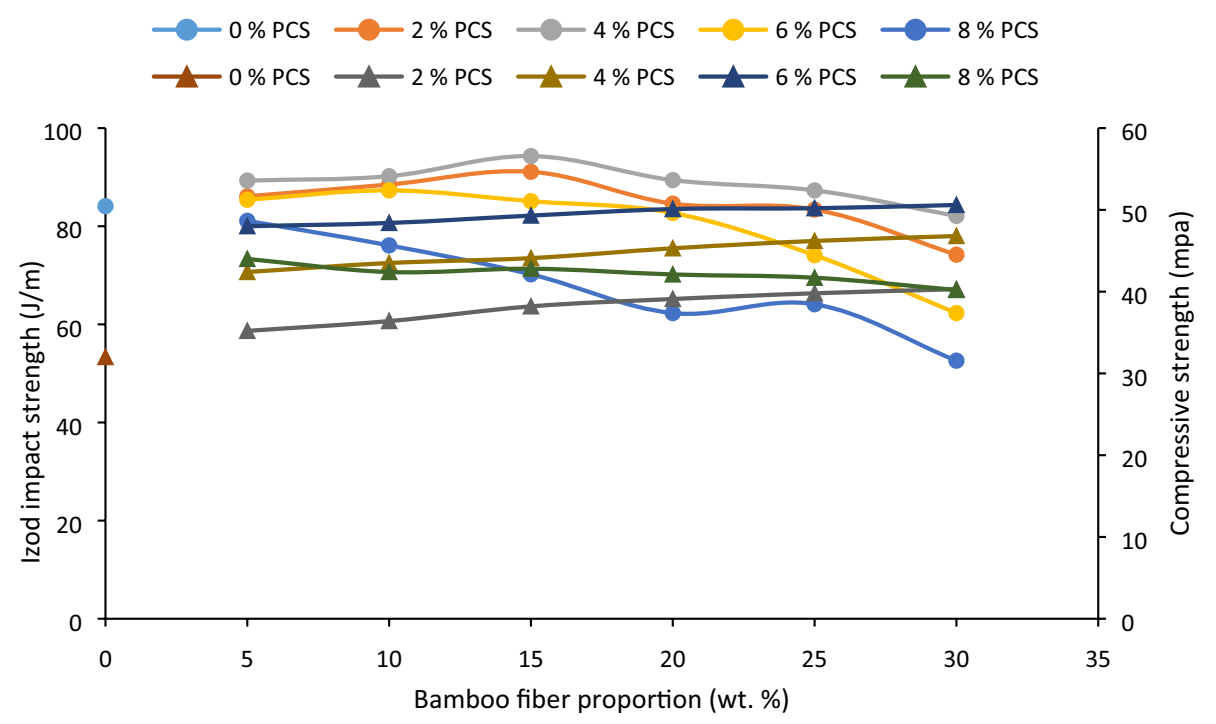

Figure 5. Influence of bamboo fiber fraction on Izod impact strength and compressive strength for 0, 5, 10, 15, 20,25 and $30 \mathrm{wt} \%$ fiber loading.

by Ref. ${ }^{77}$ show a lowering of density as the coconut shell powder filler increased, further corroborating in this study. In this study, the density of the composite depreciated with increasing fiber loading from 10 to $30 \mathrm{wt} \% \mathrm{BF}$. Incorporation of bamboo fiber and coconut shell powder resulted in lowering of densities. Lowering of density of BP/PCS PVC composite is beneficial in that the laptop must be light weight for easier carriage and portability. Diminishing values in density can be associated with lower density of fiber compared to the polymer.

Water retention. Water absorption results for samples reinforced with BF/PCS of varied proportion are as illustrated in Fig. 4. Water retention (\%) trended upward with PCS proportion owing to the hydrophilic nature of the particulate $^{78}$. Authors ${ }^{79}$ confirmed this result as par coconut shell powder addition. Water retention rose as PCS increased on the introduction of PCS from 2 to $6 \mathrm{wt} \%$ intermixed with BF from 5 to $30 \mathrm{wt} \%$. A distinct finding made was that the incorporation of $8 \mathrm{wt} \%$ gave a steady increase when blended with 5 and $10 \%$ BF. Further blending of 15-20 wt\% BF, there was an exponential rise in water retention accruing to the fact that PCS and BF fiber, which are hydrophilic, are occupying more volume resulting in higher water retention. Moreover, at that proportion, water penetration weakens the bond between fiber and matrix causing fiber detachment, hence leading to more water suction. Author ${ }^{80}$, studied the effect of coconut shell powder on the properties of polyurethane and he observed an increase in water absorption of the matrix with further addition of the biofiller. Just as obtained in ${ }^{81,82}$, water retention increased with BF addition. Further corroboration to this work is expressed in $^{83-85}$.

Impact strength and compressive strength. Impact strength. Impact strength of the composites developed with respect to bamboo fiber/particulate coconut shell additive as presented in Fig. 5 was observed to rise with fiber loading from 5 to $30 \mathrm{wt} \%$ for samples knitted with $2 \mathrm{wt} \%$ PCS. Intermix of $5-15 \mathrm{wt} \% \mathrm{BF}$ and $4 \mathrm{wt} \%$ PCS also enhanced the impact strength. Enhanced interfacial adhesion and even distribution of fillers within a matrix reducing interparticle distance provoke even stress distribution within the matrix thereby effectuating higher impact strength ${ }^{86}$. However, intermix of 20-30 wt\% fiber and 2/4/6 wt\% PCS resulted in depreciation in impact strength and this is ascribed to fiber agglomeration which serves as portion of stress concentration; thereby instigating brittleness within matrix. Interface at 6/8 wt\% PCS at fiber loading of 5 and $10 \mathrm{wt} \%$ improved the impact strength and this can be credited to even stress distribution and enhanced interaction between fibers and particles under stress. However, at 6 and $8 \mathrm{wt} \%$ the the tendency for particle agglomeration increased, a consequence of which resulted in the lowering of strength at fiber loading 15-30 wt\%. Observations made in this study can be linked to the study of ${ }^{87}$ in which the impact strength reduced with fiber loading up to $30 \mathrm{wt} \%$. Similarly, wood fiber incorporated into polypropylene was reported to reduce the impact strength at increased fiber loading up to $40 \mathrm{wt} \%{ }^{88}$.

The test was carried out on cylindrical samples of composites $40 \mathrm{~mm}$ in diameter and $80 \mathrm{~mm}$ in length and carried out as per ASTM D $695^{53}$. From Fig. 5, the compressive strength appreciated significantly with PCS loading from 2 to $8 \mathrm{wt} \%$ for all proportion of fiber content. Further observation is the marginal rise in compressive strength with fiber loading when considering the effect of the fiber on the strength under 2,4 , and $8 \%$ PCS. It can be inferred that particulate has a significant effect on the composites while BF has marginal effect on the compressive strength of the composite. Compressive strength was observed to peak at $55.2 \mathrm{MPa}$, an increase of $72.5 \%$ rise (relative to compressive strength of control $0 \mathrm{wt} \% \mathrm{PCS} / \mathrm{BF}$ ) associated with the even distribution of PCS particles within the matrix. Compressive strength was detected to reduce at $8 \mathrm{wt} \%$ PCS loading. Agglomeration of particles is responsible for this, hence, during loading, residual stress were stored, amounting to lower 


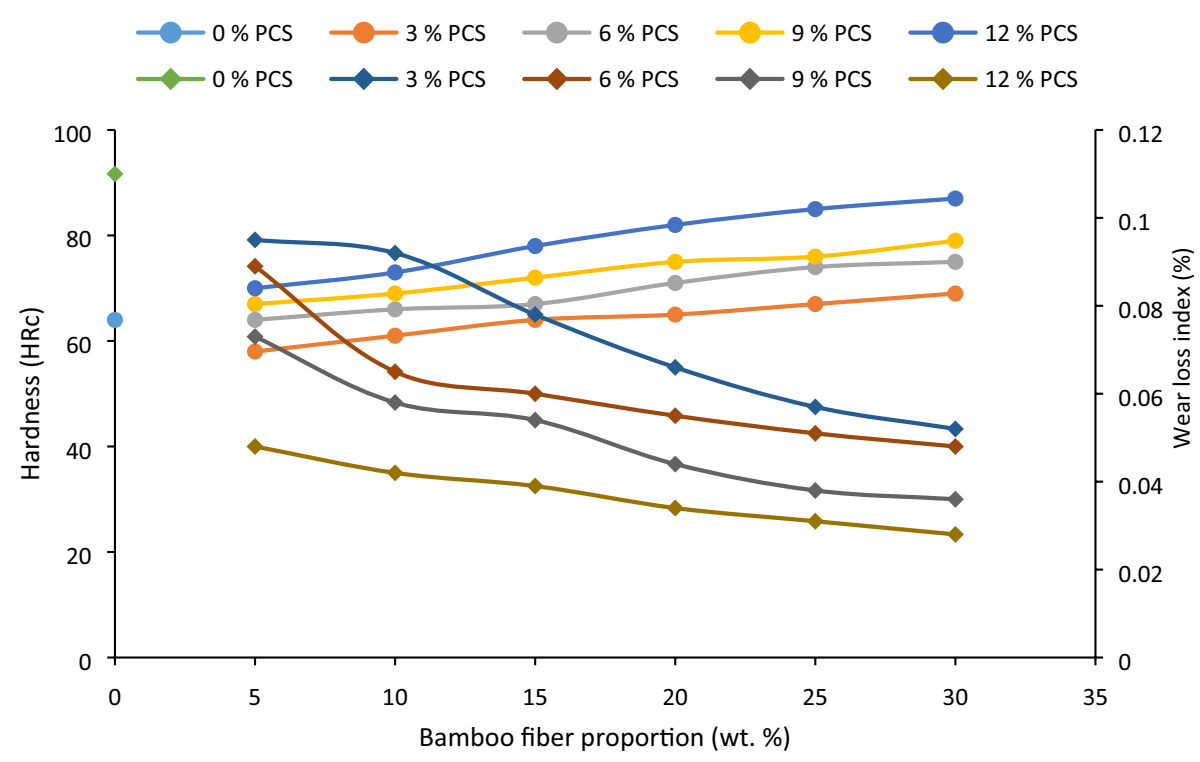

Figure 6. Influence of bamboo fiber fraction on hardness and wear loss index for 0, 5, 10, 15, 20, 25 and $30 \mathrm{wt} \%$ fiber loading.

strength against compressive stress. Observation depicted in ${ }^{89}$ corroborates the findings noted in this study as compressive strength reduced at $8 \mathrm{wt} \%$ fiber loading.

Hardness and wear. Hardness. Hardness was observed to increase with particulate and fiber bonding (Fig. 6). Enhanced interfacial adhesion promotes hardness which may be due to the strong adhesion of alkaline treated BF to PVC matrix. Additionally, PCS presence serves as a filler reducing the interparticle distance, repercussion of which amounted to improved hardness. Maximum hardness was attained at intermix at $30 \mathrm{wt} \% \mathrm{BF}$ and $8 \mathrm{wt} \%$ PCS, a rise of $61 \%$. Results obtained by Ref. ${ }^{90}$ revealed a progressive rise in hardness from 0 to $20 \%$ fiber used even as confirmed in this study.

The hardness depicted in this study conforms to the findings of ${ }^{91}$ where shore hardness was reported to increase with rising glass fiber/titania particles intermix. Authors ${ }^{78}$ also affirmed the increased Rockwell hardness of polymer matrix reinforced with coconut shell powder.

Wear. Wear resistance of the composite was evaluated by measuring weight loss during test. Lower weight loss depicts higher abrasion resistance (Fig. 6). Similar to the study of ${ }^{92}$ who studied the wear behaviour of polyvinyl pyrrolidone composite incorporated with date palm leave fiber. It was observed in the study that weight loss reduced with fiber loading irrespective of the load applied during test. Similar result was reported by Ref. ${ }^{93}$ the wear rate reduced as the percentage carbonized bone increased.

Increase in abrasion resistance with fiber and particulate loading is traceable to the enhanced cohesion within particles of the composites enabled by the fusion of coconut shell particles in the matrix. Fiber inclusions may also promotes abrasion resistance due to strong attachment to the matrix. The study of ${ }^{94}$ depicted a reduction in wear rate by increasing coir powder and coir fiber content. Wear rate was noted to decrease with increasing coir powder loading down to $25 \%$. As observed in this study, wear loss was more pronounced with increasing powder presence than fiber, which is associated with ease of disengagement of particles than fiber ${ }^{95}$.

Thermal and electrical conductivity. Thermal conductivity. Thermal conductivity of the composite developed increased marginally with PCS loading as presented in Fig. 7. Introduction of PCS led to a reduction of porosity promoting cohesion within particles in the matrix; thereby enhancing interparticle interaction. Thermal activation of particles amounts to excitation and gyration enabling the transfer of thermal energy from one particle to the next. Previous studies on the composite revealed an appreciation in thermal conductivity with a rise in copper particulate fraction ${ }^{96}$ and further confirmed by Ref. ${ }^{97}$.

Proportional rise in BF incorporated shows a lowering of thermal conductivity despite it has been treated. Natural fibers are characterized with inherent pores and higher volume presence in matrix, introduce a slight rise in porosity, and in effect, leads to a decrease in thermal conductivity owing to the distance between particles and the possible bridges in thermal transmission. This trend was in line with study carried out by Ref. ${ }^{98}$. Previous studies of ${ }^{99}$, revealed the decrease in thermal conductivity with increasing abaca fiber due to increase void with fiber loading, an observervation further corroborated in ${ }^{100}$.

Electrical conductivity. Coconut shell powder and bamboo fiber have poor electrical conductivity ${ }^{101,102}$. Presence of PCS in increasing proportion reduced the electrical conductivity (Fig. 7). With higher fiber fraction, the 


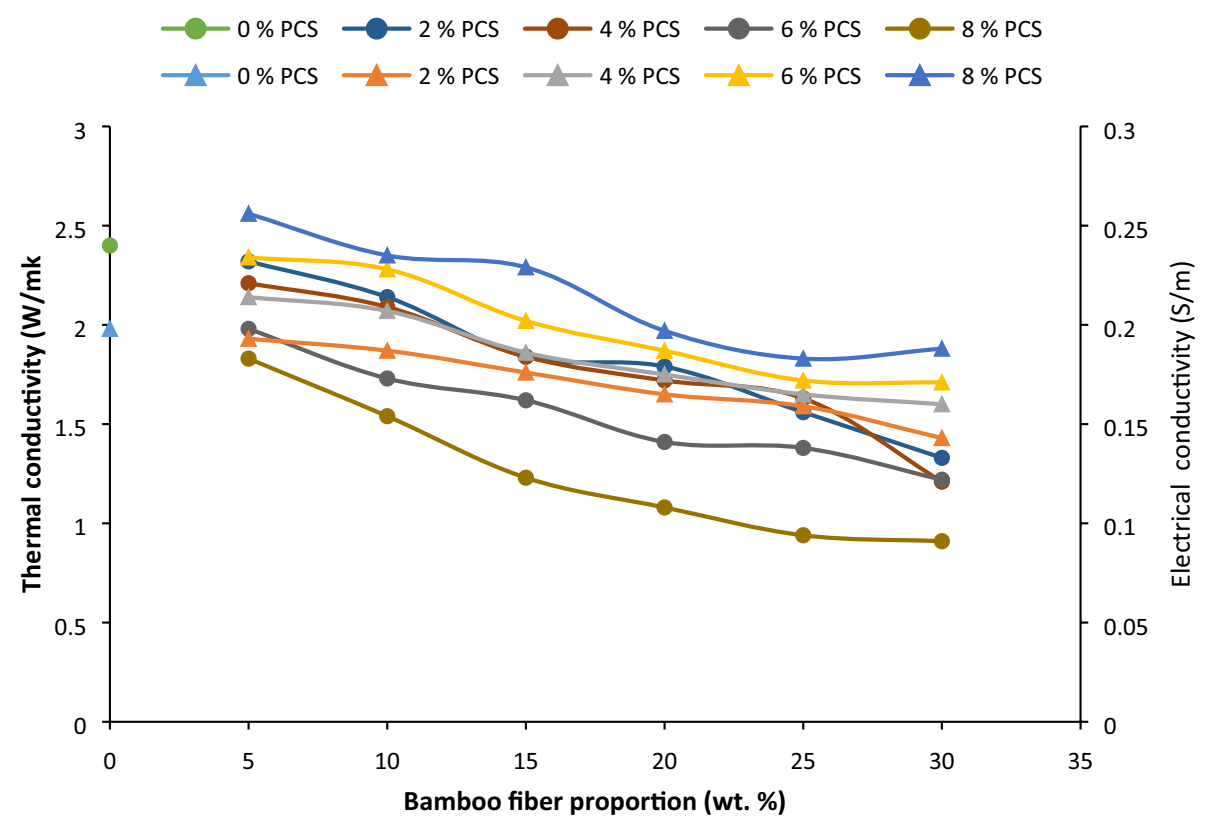

Figure 7. Influence of bamboo fiber fraction on thermal conductivity and electrical conductivity for $0,5,10$, $15,20,25$ and 30 wt\% fiber loading.

electrical conductivity also depreciated ${ }^{103}$. Lower electrical conductivity shows enhanced insulation properties, hence qualifying for insulation application. Lowest conductivity was reported at $30 \mathrm{wt} \% \mathrm{BF}$ and $8 \mathrm{wt} \%$ PCS $(0.91 \mathrm{~S} / \mathrm{m})$ gives $62 \%$ enhancement reduction in thermal conductivity with respect to control. From the report, increasing the proportion of BF and PCS enhances the insulation properties.

Morphological analysis. The representative morphological features of composite samples developed are as displayed in Fig. 8.

Figure 8 presents morphological images of selected samples representing the selected mixes of images presenting microstructural features. Particulate distribution in high quantity amounts to agglomeration of particles as indicated in Fig. 8b,c, and h. These points of agglomeration serve as the stress concentration points eventually amounting to the lowering of strength as observed under compressive strength and impact strength. Figure $8 \mathrm{~d}$ reflected the fiber observed fiber overlap within the matrix, which eventually amounts to fiber clog as seen in Fig. $8 \mathrm{~h}$, the consequence of which reduces strength on the dint of uneven stress distribution. Coalesce of fibers and particulates (Fig. 8a,e,f, and g) indicates even stress distribution among particulates, fibers and matrix enhancing strength. Consequence of this was reflected in the increase in tensile and flexural strength, moduli of elasticity and rupture, impact strength, and compressive strength. The closeness of these particles by dint of reduced interparticle distances allows the transfer of heat when thermally agitated, eventually causing a rise in thermal conductivity as reflected in the uptrend in thermal conductivity with increasing PCS loading. However, based on the lower conductivity of the fiber, the conductivity reduced with increasing fiber loading. Inverse position was taken as the par electrical conductivity in that increasing proportion of fibers and particulates presented depreciation in the property value based on incoherence distribution of fibers and particulates as observed in the micrographs (Fig. 8c,d, and h).

\section{Conclusions}

Treated bamboo fiber/particulate coconut shell hybrid PVC composite was examined for tensile, flexural, impact, and compressive strengths; moduli of elasticity and rupture. Other properties include hardness, wear loss index, water retention, thermal, and electrical conductivity. Results presented indicated that;

i. incorporation of $5,10,15,20,25$, and $30 \mathrm{wt} \%$ bamboo fiber at $2 \mathrm{wt} \%$ constant particulate coconut shell resulted in enhancement of yield strength, modulus of elasticity, flexural strength and modulus of rupture, of which bamboo fiber proportion of 35 and $40 \mathrm{wt} \%$ resulted in strength depreciation. Similarly, particulate coconut shell addition of 4,6 , and $8 \mathrm{wt} \%$ instigates sdecrease in strength.

ii. thermal conductivity reduced consistently with increased fiber loading but slightly increase with increased particulate loading. Electrical conductivity reduced with increased fiber and particulate loading.

iii. Interfuse of 5, 10,15 wt\% fiber and 2 and $4 \mathrm{wt} \%$ particulate is effective in enhancing impact strength of which proportions beyond this is detrimental to impact strength of the composites. Compressive strength was better boasted with increasing fiber fraction and PCS amount but 8 wt\% PCS amounted to depreciation in trend. 

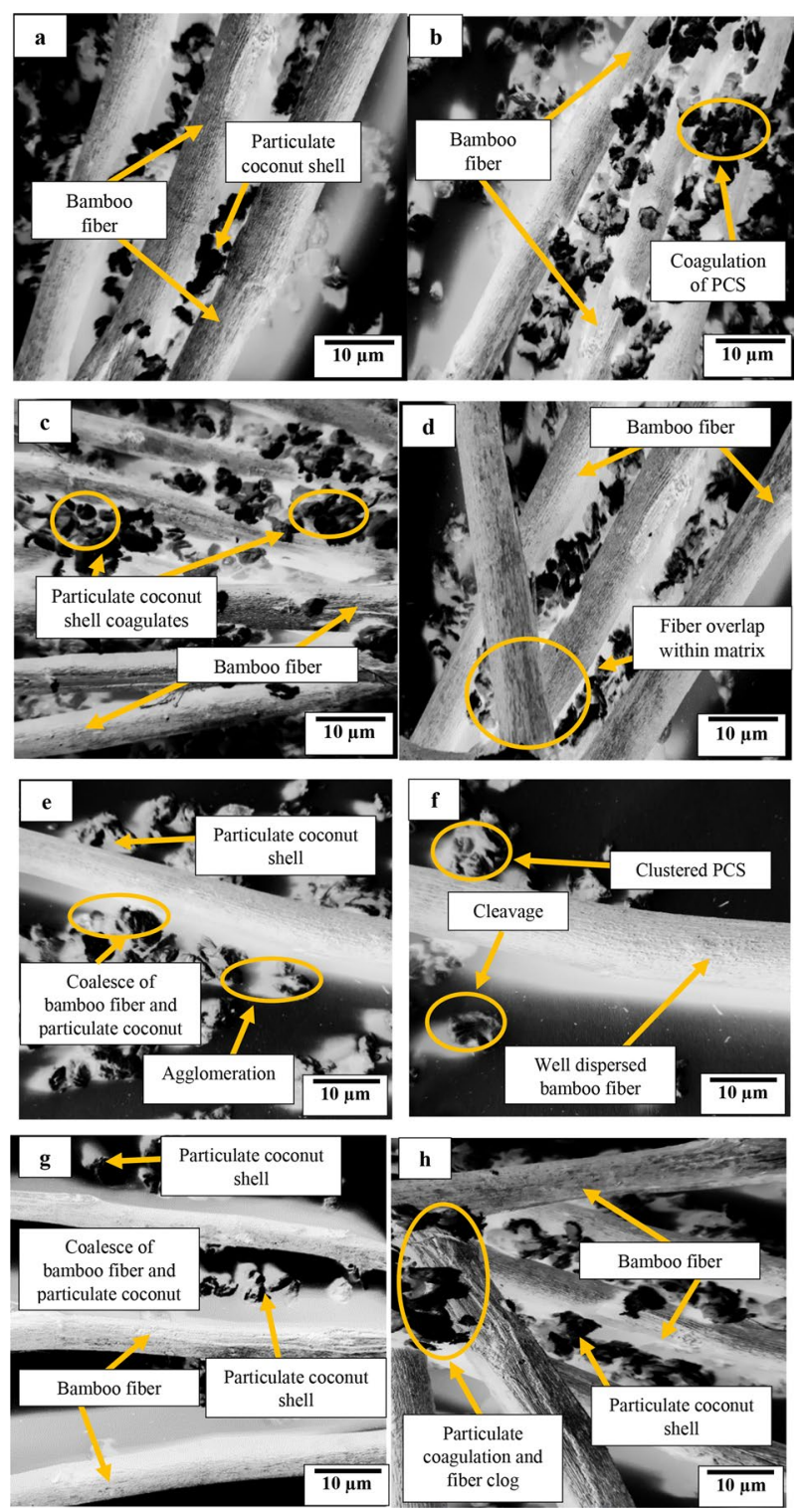

Figure 8. Morphological SEM image of compsoites amples reinforced with (a) 4 wt $\% \mathrm{PCS} / 20 \mathrm{wt} \% \mathrm{BF}$ (b) 4 wt $\%$ PCS $/ 25$ wt $\%$ BF (c) 4 wt $\%$ PCS $/ 30$ wt $\%$ BF (d) 2 wt $\%$ PCS $/ 20$ wt $\%$ BF (e) 4 wt $\%$ PCS 3 wt $\%$ BF (f) 2 wt $\%$ $\mathrm{PCS} / 5 \mathrm{wt} \% \mathrm{BF}$ (g) $2 \mathrm{wt} \%$ PCS/30 wt\% BF (h) $4 \mathrm{wt} \% \mathrm{PCS} / 30 \mathrm{wt} \%$ BF.

iv. blending of the two variable inputs; $5,10,15,20,25$, and $30 \mathrm{wt} \% \mathrm{BF}$ and $2 \mathrm{wt} \%$ PCS presented better enhancement in properties of composite developed and can be utilized in development of insulating pipes and ceiling boards.

\section{Data availability}

All data generated or analysed during this study are included in this published article.

\section{Code availability}

No code was used for the computation of the data reported in this study.

Received: 17 November 2020; Accepted: 2 February 2021

Published online: 09 March 2021

\section{References}

1. Fiore, V., Di Bella, G. \& Valenza, A. The effect of alkaline treatment on mechanical properties of kenaf fibers and their epoxy composites. Compos. B Eng. 68(2015), 14-21 (2015).

2. Oladele, I. O., Akinwekomi, A. D., Agbabiaka, O. G. \& Oladejo, M. O. Influence of biodegradation on the tensile and wear resistance properties of bio-derived $\mathrm{CaCO}_{3}$ /epoxy composites. J. Polym. Res. 26, 1-9 (2019). 
3. Oladele, I. O., Ajileye, J. O., Oke, S. R., Daramola, O. O. \& Adewumi, O. A. Thermal and water absorption properties of biosynthetic hybrid reinforced polypropylene composites. Mater. Today Proc. https://doi.org/10.1016/j.matpr.2020.05.580 (2020).

4. Pandey, J. K., Ahn, S. H., Lee, C. S., Mohanty, A. \& Misra, M. Recent advances in the application of natural fiber based composites. Macromol. Mater. Eng. 295, 975-989 (2010).

5. Mochane, M. J. et al. Recent progress on natural fiber hybrid composites for advanced applications: a review. Express Polym. Lett. 13(2), 159-198 (2019).

6. Salmah, H., Romisuhani, A. \& Akmal, H. Properties of low-density polyethylene/palm kernel shell composites: effect of polyethylene co-acrylic acid. J. Thermoplast. Compos. Mater. 26, 3-15. https://doi.org/10.1177/0892705711417028 (2011).

7. Jurczyk, S. et al. (Bio)degradable polymeric materials for sustainable future-Part 2: degradation studies of $\mathrm{P}(3 \mathrm{HB}-c o-4 \mathrm{HB}) /$ cork composites in different environments. Polymers. 11, 547. https://doi.org/10.3390/polym11030547 (2019).

8. Balart, R., Montanes, N., Dominici, F., Boronat, T. \& Torres-Giner, S. Environmentally friendly polymers and polymer composites. Materials 13, 4892. https://doi.org/10.3390/ma13214892 (2020).

9. Oladele, I. O. et al. Development of ecofriendly snail shell particulate-reinforced recycled waste plastic composites for automobile application. Sci. World J. 2020, 8. https://doi.org/10.1155/2020/7462758 (2020).

10. Ming, P. T. S., Bao, C. A., Kamarudin, S. \& Ying, C. S. The potencial of oil palm ash and eggshell powder as hybrid biofillers in natural rubber biocomposites. IOP Conf. Ser. Mater. Sci. Eng. 859, 012013. https://doi.org/10.1088/1757-899X/1/012013 (2020).

11. Das, M. \& Chakraborty, D. Evaluation of improvement of physical and mechanical properties of bamboo fibers due to alkali treatment. J. Appl. Polym. Sci. 107, 522-527 (2008).

12. Jawaid, M., Abdul Khalil, H. P. S., Hassan, A., Dungani, R. \& Hadiyane, A. Effect of jute fibre loading on tensile and dynamic mechanical properties of oil palm epoxy composites. Compos. B Eng 45, 619-624. https://doi.org/10.1016/j.composites b.2012.04.068 (2013).

13. Abdul Khalil, H. P. S. et al. Development and material properties of new hybrid medium density fibreboard from empty fruit bunch and rubberwood. Mater. Des. 31(9), 4229-4236 (2010).

14. Alomayri, T., Vickers, L., Shaikh, F. U. A. \& Low, I. M. Mechanical properties of cotton fabric reinforced geopolymer composites at $200-1000^{\circ} \mathrm{C}$. J. Adv. Ceram. 3, 184-193. https://doi.org/10.1007/s40145-014-0109-x (2014).

15. Li, Z., Zhou, X. \& Pei, C. Effect of sisal fiber surface treatment on properties of sisal fiber reinforced polylactide composites. Int. J. Polym. Sci. 2011, 1-7. https://doi.org/10.1155/2011/803428 (2011).

16. Manikandan, A. \& Rajkumar, R. Evaluation of mechanical properties of synthetic fiber reinforced polymer composites by mixture design analysis. Polym. Polym. Compos. 24(7), 455-462 (2016).

17. Santos, M. J. N., Delgado, J. M. P. Q. \& Barbosa de Lima, A. G. Synthetic fiber-reinforced polymer composite manufactured by resin transfer moulding technique: foundation and engineering applications. Diffus. Found. 14, 21-42 (2017).

18. Rohit, K. \& Dixit, S. A review-future aspect of natural fiber reinforced composite. Polym. Renew. Resour. 7(2), 43-60. https:// doi.org/10.1177/204124791600700202 (2016).

19. Ahmad, F., Choi, H. S. \& Park, M. K. A review: natural fiber composites selection in view of mechanical, light weight, and economic properties. Macromol. Mater. Eng. https://doi.org/10.1002/mame.201400089 (2014).

20. Azam, A. et al. Hydrophobic treatment of natural fibers and their composites-a review. J. Ind. Test. 47(8), 1-46. https://doi. org/10.1177/1528083716654468 (2016).

21. Mohanty, A. K., Misra, M. \& Drzal, L. T. Surface modification of natural fibers and performance of the resulting biocomposites: an overview. Compos. Interfaces 8(5), 313-343 (2001).

22. Mohammed, L., Ansari, M. N. M., Pua, G., Jawaid, M. \& Saiful Islam, M. A review on natural fiber reinforced polymer composite and its applications. Int. J. Polym. Sci. 2015, 1-15. https://doi.org/10.1155/2015/243947 (2015).

23. Faruk, O., Bledzki, A. K., Fink, H.-P. \& Sain, M. Biocomposites reinforced with natural fibers: 2000-2010. Prog. Polym. Sci. 37(11), 1552-1596 (2012).

24. Venkateshwaran, N., Elaya Perumal, A. \& Arunsundaranayagam, D. Fiber surface treatment and its effect on mechanical and visco-elastic behaviour of banana/epoxy composite. Mater. Des. 47, 151-159 (2013).

25. Cai, M., Takagi, H., Nakagaito, A. N., Li, Y. \& Waterhouse, G. I. Effect of alkali treatment on interfacial bonding in abaca fiberreinforced composites. Compos. Part A 90, 589-597 (2016).

26. Kalia, S., Kaushik, V. K. \& Sharma, R. K. Effect of benzoylation and graft copolymerization on morphology, thermal stability, and crystallinity of sisal fibers. J. Nat. Fibers 8(1), 27-38. https://doi.org/10.1080/15440478.2011.551002 (2011).

27. Kalia, S., Kaith, B. S. \& Kaur, I. Pretreatments of natural fibres and their application as reinforcing material in polymer composites-a review. Polym. Eng. Sci. 49, 1253-1272. https://doi.org/10.1002/pen.21328 (2009).

28. Xie, Y., Hill, C. A. S., Xiao, Z., Militz, H. \& Mai, C. Silane coupling agents used for natural fiber/polymer composites: a review. Compos. Part A Appl. Sci. Manuf. 41(7), 806-819 (2010).

29. Suardana, N. P. G., Ku, M. S. \& Lim, J. K. Effects of diammonium phosphate on the flammability and mechanical properties of bio-composites. Mater. Des. 32(4), 1990-1999 (2011).

30. Suoware, T. O. \& Edelugo, S. O. Fabrication of oil palm fibre polymer composite panel: impact of hybridized flame retardant formulations on thermo-mechanical properties. J. Mater. Sci. Eng. 7, 1000472. https://doi.org/10.4172/2169-0022.1000472 (2018).

31. Daramola, O., Akinwekomi, A., Adediran, A., Akindote-White, O. \& Sadiku, R. Mechanical performance and water uptake behaviour of treated bamboo fibre-reinforced high-density polyethylene composites. Heliyon 5(7), e02028. https://doi.org/10.1016/j. heliyon.2019.e02028 (2019).

32. Zhang, K. et al. Thermal and mechanical properties of bamboo fiber reinforced epoxy composites. Polymers 10(6), 608. https:// doi.org/10.3390/polym10060608 (2018).

33. Yang, F. et al. Mechanical and biodegradation properties of bamboo fiber-reinforced starch biodegradable composites. J. Appl. Polym. Sci. 137(20), 48694. https://doi.org/10.1002/app.48694 (2019).

34. Chattopadhyay, S. K., Khandal, R. K., Uppalari, R. \& Ghosal, A. K. Bamboo reinforced polypropylene composites and their mechanical, thermal and morphological properties. J. Appl. Polym. Sci. 119(3), 1619-1626. https://doi.org/10.1002/app.32826 (2011).

35. Abdul Khalil, H. P. S. et al. Bamboo fiber reinforced biocomposites: a review. Mater. Des. 42, 353-368. https://doi.org/10.1016/j. matdes.2012.06.015 (2012)

36. Liu, H. et al. Compactibilizing and toughening bamboo flour-filled HDPE composites: mechanical properties and morphologies. Compos. Part A Appl. Sci. 39, 1891-1900 (2008).

37. Oladele, I. O. et al. Mechanical and wear behaviour of pulverised poultry eggshell/sisal fiber hybrid reinforced epoxy composites. Mater. Res. Express 7, 1-12. https://doi.org/10.1088/2053-1591/ab8585 (2020).

38. Oladele, I. et al. Modified palm kernel shell fiber/particulate cassava peel hybrid reinforced epoxy composites. Results Mater. 5 , 1-7. https://doi.org/10.1016/j.rinma.2019.100053 (2019).

39. Oladele, I. O. et al. Influence of designated properties on the characteristics of dombeya buettneri fiber/graphite hybrid reinforced polypropylene composites. Sci. Rep. 10, 11105. https://doi.org/10.1038/s41598-020-68033-y (2020).

40. Mohan, K., Abhishek, B., Prithviraj, M., Raghavendra, A. \& Vinay, P. Study on the effect of varying volume fraction on mechanical properties of coconut shell powder reinforced epoxy composite. IOP Conf. Ser. Mater. Sci. Eng. 376, 012097. https://doi. org/10.1088/1757-899X/376/1/012097 (2018). 
41. Salmah, H., Marliza, M. \& Teh, P. L. Treated coconut shell reinforced unsaturated polyester composite. Int. J. Eng. Technol. 13(02), 94-103 (2013).

42. Hemath, R., Sekar, M. \& Suresha, B. Effects of fibers and fillers on mechanical properties of thermoplastic composites. Indian J. Adv. Chem. Sci. 2, 28-35 (2014).

43. Eng, C. C., Ibrahim, N. A., Zainuddin, N., Ariffin, H. \& Yunus, W. Z. W. Impact strength and flexural properties enhancement of methacrylate silicate treated oil palm mesocarp fiber reinforced biodegradable hybrid composites. Sci. World J. 2014, 8. https ://doi.org/10.1155/2014/213180 (2014).

44. Adeosun, S. O., Gbenebor, O. P. \& Udeme, F. A. Influence of organic fillers on physiochemical and mechanical properties of unsaturated polyester composites. Arab. J. Sci. Eng. 41, 4153-4159. https://doi.org/10.1007/s13369-016-2120-8 (2016).

45. Lu, T. et al. Effects of modification of bamboo cellulose fibers on the improved mechanical properties of cellulose reinforced poly(lactic acid) composites. Compos. Part B 62, 191-197. https://doi.org/10.1016/j.compositesb.2014.02.030 (2014).

46. Zhang, K. et al. Thermal and mechanical properties of bamboo fiber reinforced epoxy composites. Polymers. 10, 608. https:// doi.org/10.3390/polym10060608 (2018).

47. ASTM D6913/D6913M-17. Standard Test Method for Particle-Size Distribution (Gradation0 of Soils Using Sieve Analysis (ASTM International, West Conshohocken, PA, 2017).

48. ASTM D3039/D3039M-17. Standard Test Method for Tensile Properties of Polymer Matrix Composite Materials (ASTM International, West Conshohocken, PA, 2017).

49. ASTM D 638-14. Standard Test Method for Tensile Properties of Plastics (International, West Conshohocken, PA, 2017).

50. ASTM D790-17. Standard Test Methods for Flexural Properties of Unreinforced and Reinforced Plastics and Electrical Insulating Materials (ASTM International, West Conshohocken, PA, 2017).

51. ASTM D5229M-12. Standard Test Method for Moisture Absorption Properties and Equilibrium Conditioning of Polymer Matrix Composite Materials (ASTM International, West Conshohocken, PA, 2012).

52. ASTM D256-10. Standard Test Methods for Determining the Izod Pendulum Impact Resistance of Plastics (ASTM International, West Conshohocken, PA, 2018).

53. ASTM D 695-15. Standard Test Method Compressive Properties of Rigid Plastics (ASTM International, West Conshohocken, PA, 2015).

54. ASTM D 785-08. Standard Test Method Rockwell Hardness of Plastics and Electrical Insulating Materials (ASTM International, West Conshohocken, PA, 2015).

55. ASTM D1044-13. Standard Test Method for Resistance of Transparent Plastics to Surface Abrasion (ASTM International, West Conshohocken, PA, 2013).

56. ASTM E1530-19. Standard Test Method for Evaluating the Resistance to Thermal Transmission by the Guarded Heat Flow Meter Technique (ASTM International, West Conshohocken, PA, 2019).

57. ASTM D 257-14. Standard Test Method for DC Resistance or Conductance of Insulating Materials (ASTM International, West Conshohocken, PA, 2014).

58. Daramola, O. O. et al. Mechanical properties of high density polyethylene matrix composites reinforced with chitosan particles. Mater. Today Proc. https://doi.org/10.1016/j.matpr.2020.03.695 (2020).

59. Bertinez, A. N., Monzon, M., Angulo, I. M. \& Ortega, Z. Treatment of banana fiber for use in the reinforcement of polymeric matrices. Measurement 46(3), 1065-1073. https://doi.org/10.1016/j.measurement.2012.11.021 (2013).

60. Garcia, M., Marchese, J. \& Ochoa, N. A. Effect of the particle size and particle agglomeration on composite membrane performance. J. Appl. Polym. Sci. 118(4), 2417-2424. https://doi.org/10.1002/app.32274 (2010).

61. Haque, M. et al. Coir fiber reinforced polypropylene composites: physical and mechanical properties. Adv. Compos. Mater. 19, 91-106. https://doi.org/10.1163/092430409X12530067339325 (2010).

62. Haque, M. M., Hasan, M., Islam, M. S. \& Ali, M. E. Physico-mechanical properties of chemically treated palm and coir fiber reinforced polypropylene composites. Bioresour. Technol. 100, 4903-4906. https://doi.org/10.1016/j.biortech.2009.04.072 (2009).

63. Haque, M. M. \& Islam, M. N. A study on the mechanical properties of urea treated coir reinforced polypropylene composites. J. Thermoplast. Compos. Mater. 26(2), 139-155. https://doi.org/10.1177/0892705711419698 (2011).

64. Mir, S. S., Nafsin, N., Hasan, M., Hasan, N. \& Hassan, A. Improvement of physico-mechanical properties of coir-polypropylene biocomposites by fiber chemical treatment. Mater. Des. 52, 251-257. https://doi.org/10.1016/j.matdes.2013.05.062 (2013).

65. Oladele, I. O. et al. Modified palm kernel shell fiber/particulate cassava peel hybrid reinforced epoxy composites. Results Mater. 5, 1-8. https://doi.org/10.1016/j.rinma.2019.100053 (2020).

66. Szabo, L. et al. Short carbon fiber reinforced polymers: utilizing lignin to engineer potentially sustainable resource-based biocomposites. Front. Chem. 7, 757. https://doi.org/10.3389/fchem.2019.00757 (2019).

67. Seth, S. A., Aji, I. S. \& Tokan, A. Effects of particle size and loading on tensile and flexural properties of polypropylene reinforced doum palm shell particles composites. Am. Sci. Res. J. Eng. Technol. Sci. 44(1), 231-239 (2018).

68. Onuegbu, G. C. \& Igwe, I. O. Studies on properties of egg shell and fish bone powder filled polypropylene. Am. J. Polym. Sci. 2(4), 56-61 (2012).

69. Bhasker, J. \& Singh, V. K. Physical and mechanical properties of coconut shell particles reinforcement-epoxy composite. J. Mater. Environ. Sci. 4(2), 227-232 (2012).

70. Daramola, O. O. et al. Mechanical and wear behaviour of polylactic acid matrix composites reinforced with crab-shell synthesized chitosan microparticles. Mater. Today Proc. https://doi.org/10.1016/j.matpr.2020.05.599 (2020).

71. Hitoshi, T. \& Ichihara, Y. Effect of fiber length on mechanical properties of "green" composites using a starch-based resin and short bamboo fibers. JSME Int. J. Ser. A https://doi.org/10.1299/jsmea.47.551 (2004).

72. Sushanta, K. S., Mohanty, S. \& Nayak, S. K. Banana/glass fiber-reinforced polypropylene hybrid composites: fabrication and performance evaluation. Polym. Plast. Technol. Eng. 48, 397-414 (2009).

73. Siddika, S., Mansura, F., Hasan, M. \& Hassan, A. Effect of reinforcement and chemical treatment of fiber on the properties of jute-coir fiber reinforced hybrid polypropylene composites. Fibers Polym. 15(5), 1023-1028. https://doi.org/10.1007/s1222 1-014-1023-0 (2014).

74. Islam, M. N., Rahman, M. R., Haque, M. M. \& Huque, M. M. Physico-mechanical properties of chemically treated coir reinforced polypropylene composites. Compos. Part A 41, 192-198. https://doi.org/10.1016/j.compositesa.2009.10.006 (2010).

75. Saw, S. K., Sarkhel, G. \& Choudhury, A. Preparation and characterization of chemically modified jute-coir hybrid fiber reinforced epoxy novolac composites. J. Appl. Polym. Sci. 125, 3038-3049. https://doi.org/10.1002/app.36610 (2012).

76. Zhang, K. et al. Thermal and mechanical properties of bamboo fiber reinforced epoxy composites. Polymers 10(608), 1-18. https ://doi.org/10.3390/polym10060608 (2018).

77. Obiukwu, O. O., Uchechukwu, M. N. \& Nwaogwugwu, M. C. Study on the properties of coconut shell powder reinforced high density polyethylene composite. Futo J. Ser. 2(2), 43-55 (2016).

78. Talabi, S., Agunsoye, J. O. \& Sanni, O. S. Study of mechanical behaviour of coconut shell reinforced polymer matrix composites. J. Miner. Mater. Charact. Eng. 11, 774-779. https://doi.org/10.4236/jmmce.2012.118066 (2012).

79. Bhaskar, J. \& Singh, V. K. Water absorption and compressive strength of properties of coconut shell particle reinforced-epoxy composite. J. Mater. Environ. Sci. 4(1), 113-118 (2012).

80. Sallal, H. A. Effect of the addition of coconut shell powder on properties of polyurethane matrix composite. Al-Nahrain Univ. Coll. Eng. J. 17(2), 203-210 (2014). 
81. Munoz, E. \& Garcia-Manrique, J. A. Water absorption behaviour and its effect on the mechanical properties of flax fiber reinforced bioexpoxy composite. Int. J. Polym. Sci. 2015, 1-10. https://doi.org/10.1155/2015/390275 (2015).

82. Kalirasu, S., Rajimi, N., Rajesh, S. \& Jerry-Michla, J. R. Water absorption behaviour on natural/synthetic fiber reinforced polymer composites. Int. J. Eng. Adv. Technol. 9(154), 1-5 (2019).

83. Zakaria, M. N. et al. The effect of alkaline treatment on water absorption and tensile properties of non-woven kenaf polyester composite. Adv. Mater. Res. 812, 258-262 (2013).

84. Ramadevi, P. R., Dhanalakshimi, S., Srinivasa, C. V. \& Basavaraju, B. D. Effect of alkaline treatment on water absorption of single cellulosic abaca fiber. BioResources 7(3), 3515-3524 (2012).

85. Isa, M. T. et al. The effect of fiber treatment on the mechanical and water absorption properties of short okro/glass fibers hybridized epoxy composites. Int. J. Mater. Eng. 4(5), 180-184. https://doi.org/10.5923/j.ijme.20140405.03 (2014).

86. Jesson, D. \& Watts, J. The interface and interphase in polymer matrix composites: effect on mechanical properties and methods for identification. Polym. Rev. 52(8), 1-40. https://doi.org/10.1080/15583724.2012.710288 (2012).

87. Eng, C. C., Ibrahim, N. A., Zainuddin, N., Ariffin, H. \& Yunus, W. Z. W. Impact strength and flexural properties enhnacement of methacrylate silane treated oil palm mesocarp fiber reinforced biodegradable hybrid comnposites. Sci. World J. 2014(213180), 1-8. https://doi.org/10.1155/2014/213180 (2014).

88. Nourbakhsh, A., Kokta, B., Ashori, A. \& Jahan-Latibari, A. Effect of a novel coupling agent, polybutadiene isocyanatecion: mechanical properties of wood-fiber polypropylene composite. J. Reinforced Plast. Compos. 27(16-17), 1679-1687. https://doi. org/10.1177/0731684407087377 (2008).

89. Dash, M. A Study on Thermal Characteristics of Epoxy Composites Filled with Natural Fiber and Particulate. MTech. Dissertation. National Institute of Technology, India (2016)

90. Durowaye, S. I., Lawal, G. I., Akande, M. A. \& Durowaye, V. O. Mechanical properties of particulate coconut shell and palm fruit polester composites. Int. J. Mater. Eng. 4(4), 141-147. https://doi.org/10.5923/j.ijme.20140404.04 (2014).

91. Marhoon, I. I. Mechanical properties of composite materials reinforced with short random glass fibers and ceramic particles. Int. J. Sci. Technol. Research. 7(8), 50-53 (2018).

92. Mohanty, J. R., Das, S. N. \& Das, H. C. Effect of fiber content on abrasive wear behaviour of date palm leaf reinforced polyvinyl pyrrolidone composite. ISRN Tribol. 2014, 1-10. https://doi.org/10.1155/2014/453924 (2014).

93. Asuka, F., Abdulwaheb, M., Aigbodion, V. S., Fayomi, O. S. I. \& Aponbiede, O. Effect of load on the wear behaviour of polypropylene/carbonized bone ash particulate composite. Egypt. J. Basic Appl. Sci. 1(1), 67-70. https://doi.org/10.1016/j.ejbas.2014.02.002 (2014).

94. Ibrahem, R. A. Friction and wear behavior of fiber/particulate reinforced polyester composites. Int. J. Adv. Mater. Res. 2(2), 22-26 (2016).

95. Wu, L., Guo, X. \& Zhang, J. Abrasive reissitant coatings-a review. Lubricants. 2, 66-89. https://doi.org/10.3390/lubricants20200 $66(2014)$.

96. Tekce, H. S., Kumulutas, D. \& Tavman, I. H. Effect of particle shape on thermal conductivity of copper reinforcement polymer composites. J. Reinforced Plast. Compos. 26(1), 113-121 (2007).

97. Alam, M. K., Islam, M. T., Mina, M. F. \& Gafur, M. A. Structural mechanical thermal and electrical properties of carbon black reinforced polyester resin. Compos. J. Appl. Polym. Sci. 131(13), 40421. https://doi.org/10.1002/app.40421 (2014).

98. Sahu Y. K. Study on the Effective Thermal Conductivity of Fiber Reinforced Epoxy Composites. MTech. Dissertation. National Institute of Technology, Rourkella, India (2014).

99. Liu, K., Zhang, X., Tagaki, H., Yang, Z. \& Wang, D. Effect of chemical treatment on transverse thermal conductivity of unidirectional abaca fiber/epoxy composite. Compos. Part A 66, 227-236. https://doi.org/10.1016/j.compositesa.2014.07.018 (2014).

100. Rasheed, A. K., Rasheed, N. K. \& Marhoon, I. I. Effects on the mechanical and physical properties of epoxy-polyurethane resin blend polymer. Eur. J. Eng. Res. Sci. 3(8), 1-4. https://doi.org/10.24018/ejers.2018.3.8.836 (2018).

101. Mochidzuki, K. et al. Electrical and physical properties of carbonized charcoals. Ind. Eng. Chem. Res. 42(21), 5140-5151. https ://doi.org/10.1021/ie030358e (2003).

102. Naik, J. \& Mishra, S. Studies on electrical properties of natural fiber: hdpe composites. Polym. Plast. Technol. Eng. 44, 687-693. https://doi.org/10.1081/PTE-200057818 (2005).

103. Haseena, A. P., Unnikrishman, G. \& Kalaprasad, G. Dielectric properties of short sisal/coir hybrid fiber reinforced natural rubber composites. Compos. Interfaces 14(7-9), 763-786. https://doi.org/10.1161/156855407782106582 (2007).

\section{Acknowledgements}

Authors appreciate Landmark University SDGs-9 Research Group (Innovation, Industry and Infrastructure) for their support.

\section{Author contributions}

A.A.A., A.A.A., and O.A.B. had the idea for the article, M.A.A.A, A.A.A, O.A.B., O.S.O., and O.S.A. performed the literature search and data analysis. A.A.A., A.A.A., O.A.B., O.S.O., O.S.A. drafted and/or critically revised the work. A.A.A., A.A.A., O.A.B., O.S.O., O.S.A. critically read and approved the final manuscript.

\section{Funding}

The authors did not receive support from any organization for the submitted work.

\section{Competing interests}

The authors declare no competing interests.

\section{Additional information}

Correspondence and requests for materials should be addressed to A.A.A.

Reprints and permissions information is available at www.nature.com/reprints.

Publisher's note Springer Nature remains neutral with regard to jurisdictional claims in published maps and institutional affiliations. 
(c) (i) Open Access This article is licensed under a Creative Commons Attribution 4.0 International cc) License, which permits use, sharing, adaptation, distribution and reproduction in any medium or format, as long as you give appropriate credit to the original author(s) and the source, provide a link to the Creative Commons licence, and indicate if changes were made. The images or other third party material in this article are included in the article's Creative Commons licence, unless indicated otherwise in a credit line to the material. If material is not included in the article's Creative Commons licence and your intended use is not permitted by statutory regulation or exceeds the permitted use, you will need to obtain permission directly from the copyright holder. To view a copy of this licence, visit http://creativecommons.org/licenses/by/4.0/.

(C) The Author(s) 2021 